\title{
Indicadores organizacionais e planejamento sucessório em empreendimentos rurais de grande porte: um estudo no estado de Mato Grosso
}

\author{
Organizational indicators and successory planning in large rural enterprises: a \\ study in the state of Mato Grosso, Brazil
Indicadores organizacionales y planificación sucesoria en grandes empresas rurales: un estudio en el estado de Mato Grosso, Brasil

\author{
Adelice Minetto Sznitowski ${ }^{1}$ \\ Priscylla Cordeiro de Sousa ${ }^{1}$ \\ Fernando Thiago ${ }^{2}$
}

Recebido em 17/10/2019; revisado e aprovado em 17/07/2020; aceito em 24/07/2020

DOI: http://dx.doi.org/10.20435/inter.v22i1.2778

\begin{abstract}
Resumo: O objetivo desta pesquisa consistiu em verificar a influência dos indicadores de gestão no planejamento de sucessão em empreendimentos rurais de grande porte. Os indicadores utilizados envolvem: liderança, decisão, controle, planejamento, comunicação e motivação das pessoas nas organizações participantes, de forma a identificar o estilo de gestão utilizado pelos seus gestores. Entende-se por sucessão familiar a transferência da gestão de um membro da família para outro membro de geração posterior. Essa questão nos empreendimentos rurais é recorrente; no entanto, as práticas de gestão supracitadas podem minimizar tal situação, o que contribui para a continuidade da organização. O método utilizado foi de base quantitativa e descritiva, utilizando a técnica de levantamento (survey). Os dados foram coletados por meio do Instrumento de Avaliação do Estilo de Gestão, que possibilita recolher informações sobre os indicadores mencionados. Os resultados dos indicadores de gestão relacionados com o planejamento sucessório evidenciam diferenças entre os dois grupos analisados: gestores membros da família e contratados não membros da família. Observou-se que os empreendimentos que planejam sucessão têm melhor percepção de seu desempenho, considerando os indicadores referentes ao estilo de gestão. Desse modo, os gestores membros da família apresentam melhor desempenho quando comparados com os gestores que não são membros da família.
\end{abstract}

Palavras-chave: empreendimentos rurais; indicadores organizacionais; planejamento de sucessão.

Abstract: The objective of this research is to verify the influence of management indicators on succession planning in large rural enterprises. The indicators used involve leadership, decision, control, planning, communication, and motivation of people in the participating organizations, in a way to identify the management style used by their managers. Family succession is the transfer of management from one family member to another member of a later generation. In rural enterprises, it is a recurring problem; however, the above-mentioned management practices can minimize this situation, which contributes to the continuity of the organization. The method used was quantitative and descriptive, using the survey technique. We collected data through the Management Style Assessment Instrument, which allows information on the mentioned indicators to be collected. The results of management indicators related to succession planning show differences between the two groups analyzed: family member managers and non-family member contractors. Enterprises that plan succession have a better perception of their performance, considering the indicators related to management style. Thus, family member managers perform better when compared to non-family member managers.

Keywords: rural enterprises; organizational indicators; succession planning.

Resumen: El objetivo de esta investigación es verificar la influencia de los indicadores de gestión en la planificación de la sucesión en las grandes empresas rurales. Los indicadores utilizados involucran: liderazgo, decisión, control, planificación, comunicación y motivación de las personas en las organizaciones participantes, con la posibilidad de identificar el estilo de gestión utilizado por sus gerentes. La sucesión familiar es la transferencia de la administración de un miembro de la familia a otro miembro de una generación posterior. En las empresas rurales, es un problema recurrente; sin embargo, las prácticas de gestión mencionadas

\footnotetext{
${ }^{1}$ Universidade do Estado de Mato Grosso (UNEMAT), Tangará da Serra, Mato Grosso, Brasil.

${ }^{2}$ Universidade Federal de Mato Grosso do Sul (UFMS), Corumbá, Mato Grosso do Sul, Brasil.
} 
anteriormente pueden minimizar esta situación, lo que contribuye a la continuidad de la organización. El método utilizado fue cuantitativo y descriptivo, utilizando la técnica de encuesta. Los datos se recopilaron a través del Instrumento de Evaluación del Estilo de Gestión, que permite recopilar información sobre los indicadores mencionados. Los resultados de los indicadores de gestión relacionados con la planificación de la sucesión muestran diferencias entre los dos grupos analizados: gerentes familiares y contratistas no familiares. Las empresas que planean la sucesión tienen una mejor percepción de su desempeño, teniendo en cuenta los indicadores relacionados con el estilo de gestión. Por lo tanto, los gerentes miembros de la familia obtienen mejores resultados en comparación con los gerentes que no son miembros de la familia.

Palabras claves: empresas rurales; indicadores organizacionales; planificación de la sucesión.

\section{INTRODUÇÃO}

Um empreendimento próspero precisa ter delineamentos estruturados, e isso requer planejamento e controle. Seu sucesso requer foco nos objetivos que a atividade suporta, no desenvolvimento de equipe, na comunicação e administração de conflito, considerando também fatores externos, como o ambiente geral, que deve ser incluído no escopo da gestão organizacional.

As organizações agropecuárias são, por vezes, rotuladas por utilizarem práticas rudimentares de gestão, baseadas no costume passado de pai para filho. Contudo, este cenário tem se alterado, especialmente provocado pelas constantes mudanças econômicas e tecnológicas. Neste aspecto, os gestores dos empreendimentos rurais, sejam proprietários, sejam funcionários, familiares ou não, devem buscar novas técnicas e práticas visando à maior assertividade e, consequentemente, ao melhor desempenho em termos de resultados.

Entre estes aspectos, a utilização de indicadores de gestão pode contribuir para a composição do sistema de controle e planejamento da organização. Indicadores esses que envolvem uma análise da gestão nos aspectos de sua prática de liderança, decisão, controle, planejamento, comunicação e motivação das pessoas, permitindo identificar o estilo de gestão utilizado pelos gestores destas organizações (THIAGO, 2017).

O entendimento do negócio rural requer visão sistêmica por envolver um conjunto de processos e sua inter-relação. Com isso, as decisões tomadas em um processo acabam por refletir nos demais; daí a importância de entender o todo e suas interfaces. Os empreendimentos que têm suas atividades planejadas obtêm melhores resultados na gestão de seus negócios, por isso a utilização de técnicas de gestão no empreendimento rural auxilia na obtenção de melhores resultados. Nesse sentido, a gestão de uma empresa é um processo que busca concretizar objetivos organizacionais com o uso de diversos recursos e o trabalho com pessoas (VILCKAS et al., 2006).

Análises sobre métodos de gestão apontam a uma diversidade quanto aos estilos de gerenciar e os efeitos nos variados ramos de empreendimentos. Estudos característicos dessa temática foram feitos por: Likert e Likert (1976), Culpan e Kucukemiroglu (1993).

As avaliações desses estudos envolvem questões a respeito do estilo, grau de participação, desempenho organizacional nos processos decisório e de gestão. Entre estas análises, destacamse as realizadas por Likert e Likert (1976) e Culpan e Kucukemiroglu (1993), por proporem os modelos de avaliar a gestão.

A busca pelos objetivos organizacionais se dá por meio do trabalho, recursos e pessoas e, por tal motivo, incluem as atividades de planejamento de sucessão. Para o Serviço Brasileiro de Apoio às Micro e Pequenas Empresas (SEBRAE, 2018), o planejamento na sucessão familiar é indispensável para a sua sobrevivência no mercado, no qual os sucessores precisam conhecer os processos administrativos da empresa para não ocorrer conflitos nessa transição. 
No contexto agropecuário, Matte e Machado (2016) destacam que os principais motivos que dificultam a sucessão é o pouco envolvimento dos filhos na gestão, pois os pais os afastam das atividades e, consequentemente, da participação na tomada de decisões e gestão dos negócios. Essa postura contribui para o despreparo na administração da propriedade e desmotiva os jovens a se interessarem pelo meio rural.

Nesse aspecto, tem-se como fator desfavorável o paternalismo do empresário rural, que centraliza todas as informações e decisões, aumentando o risco da empresa, pois a dependência de apenas um gestor causa despreparo dos sucessores para gerir o negócio. Daí a necessidade de planejar a sucessão e profissionalizar a gestão; do contrário, a empresa corre o risco de encerrar seu ciclo de vida juntamente do ciclo de vida de seu proprietário (OLIVEIRA; VIEIRA FILHO, 2018).

A gestão de empreendimentos rurais, mesmo os de grande porte, enfrenta desafios, sendo um deles o processo sucessório, questão essa complexa e pouco frequente (OLIVEIRA; VIEIRA FILHO, 2018). Diante disso, inicia-se uma fase no espaço rural marcada por dificuldades em garantir a sucessão familiar. Se, por um lado, impera a dificuldade em tratar da questão, por outro, Leonard et al. (2017) declaram que a transferência entre gerações é fundamental para a sustentabilidade e o desenvolvimento da agricultura global (LEONARD et al., 2017).

Além disso, problemas de sucessão nas organizações agropecuárias parecem ter relação com os indicadores de gestão, sendo este o objetivo desta pesquisa. Por esse motivo, entendeuse como pertinente verificar se existe influência dos indicadores de gestão no planejamento de sucessão em empreendimentos rurais de grande porte.

As propriedades rurais estão inseridas no chamado "agronegócio". O agronegócio (agribusiness) é um setor amplo, que, no entendimento de Davis e Goldberg (1957), engloba o conjunto de todas as operações e transações envolvidas desde a fabricação dos insumos agropecuários, das operações de produção nas unidades agropecuárias, até o processamento, a distribuição e o consumo dos produtos agropecuários in natura ou industrializados. Ou seja, compreende a união de todas as atividades envolvidas no setor agrícola, incorporando, entre outras: a produção agropecuária; os fornecedores de insumos agrícolas, máquinas e equipamentos; o processamento industrial; distribuição e serviços.

Considerando a amplitude do termo agronegócio, é pertinente destacar que os produtores rurais participantes da pesquisa estão inseridos no agronegócio no elo produção agropecuária e situados na região Centro-Oeste brasileira, especificamente no Estado de Mato Grosso.

Justifica-se a coleta de dados neste estado por ser o maior produtor nacional de grãos e carne bovina, sendo apontado como "celeiro do mundo". Mato Grosso vendeu para o mercado internacional 14,026 milhões de toneladas de produtos agropecuários em 2017, de acordo com as informações disponibilizadas pela Confederação de Agricultura e Pecuária do Brasil (CNA, 2018). A quantidade embarcada no 10 quadrimestre foi $18,06 \%$ superior à realizada no mesmo período de 2017, quando totalizaram 11,880 milhões ( $\mathrm{t}$ ).

Dados de 2019 citam o Estado de Mato Grosso com expressiva participação no Valor Bruto da Produção nacional. Informações levantadas pelo Ministério da Agricultura, Pecuária e Abastecimento (MAPA, 2019) citam este estado em primeiro lugar, com R\$ 90,4 bilhões; São Paulo na segunda posição, com R\$ 74,5 bilhões; seguido dos estados do Paraná (R\$ 72,9 bilhões), Minas Gerais (R\$ 54,5 bilhões) e Rio Grande do Sul (R\$ 54,3 bilhões).

As regiões Oeste e Médio-Norte mato-grossense apresentaram as maiores produtividades de soja, sendo $58,38 \mathrm{sc} / \mathrm{ha}$ e $58,10 \mathrm{sc} / \mathrm{ha}$, respectivamente, aumento de $8,1 \%$ e $2,4 \%$ quando 
comparadas com as da safra anterior, 2017-2018 (INSTITUTO MATO-GROSSENSE DE ECONOMIA AGROPECUÁRIA [IMEA], 2018).

De modo a manter a continuidade desse crescimento, os empreendimentos rurais enfrentam o desafio de implantar modelos de gestão que atendam às novas demandas produtivas e socioambientais e, ao mesmo tempo, tratem o tema sucessão, que até então é pouco frequente (OLIVEIRA; VIEIRA FILHO, 2018).

Em face do exposto, o segmento agronegócio e, nele, as unidades de produção situadas no estado de Mato Grosso foram escolhidos como objeto deste estudo, uma vez que o estado é representativo na produção agropecuária brasileira.

Fica cada vez mais evidente a importância da gestão em todos os setores, e nos empreendimentos rurais não é diferente, uma vez que os gestores desenvolvem suas atividades num contexto que envolve pessoas, processos e produtos, embora haja algumas especificidades. Observa-se que as tecnologias adotadas nas organizações rurais brasileiras são de excelência, com reconhecimento mundial, contudo, existe uma demanda para a área de gestão (SZNITOWSKI, 2017).

Nesse sentido, a abordagem aqui proposta, considerando os indicadores de gestão que envolvem aspectos de liderança, decisão, controle, planejamento, comunicação e motivação, pode contribuir para o avanço no campo da gestão em empreendimentos rurais, especialmente quando verificada sua correlação com um dos problemas recorrentes das organizações familiares e rurais, a sucessão.

\section{REFERENCIAL TEÓRICO}

\subsection{Empreendimentos rurais: características}

O termo gestão de propriedades rurais pode ser conceituado como a administração dos recursos disponíveis e potenciais visando ao melhor uso de terra, água, máquinas, equipamentos e pessoal em uma propriedade rural específica.

A propriedade rural é parte integrante dos sistemas agroindustriais, localizando-se entre dois oligopólios. De um lado, tem-se o mercado de insumos e, do outro, o de processamento, distribuição e comercialização (DAVIS; GOLDBERG, 1957). Rezende e Zylbersztajn (1999) mencionam o distanciamento existente entre o produtor e o consumidor final, visto que a relação entre ambos é dependente e intermediada pelos demais agentes da cadeia produtiva, por meio de processos comunicativos.

Desse modo, ao gerenciarem as propriedades rurais, os produtores se deparam com grande número de variáveis, como: produção animal e vegetal, fatores climáticos, planejamento de tarefas de campo, sistema financeiro e tributário, seleção de máquinas, seleção de culturas, análise de custos, regulamentos ambientais e a respeito da segurança dos trabalhadores (REZENDE; ZYLBERSZTAJN, 1999; PINTO, 2018; SZNITOWSKI, 2017; THIAGO et al., 2020).

\subsection{Sucessão}

Há quase três décadas, quando o mundo acadêmico começou a se interessar por estudos em empresas familiares, havia três verdades básicas: tratava-se de empresas pequenas, em pouca quantidade e, portanto, com pouco impacto na economia. Neste período, eram consideradas ineficientes, uma vez que a gestão da família era abordada como menos competente que a 
gestão profissional. Contudo, ao longo dos anos, essas afirmativas não mais prevalecem, uma vez que mais de $90 \%$ dos negócios na América do Norte são constituídos de empresas familiares, representando alto impacto na economia e na geração de empregos (DYER JR.; DYER, 2009).

Empresas familiares são organizações nas quais o controle da gestão pertence a uma família, seja por deter a maior proporção do capital da empresa, seja por acordo com acionistas, podendo o capital ser por quotas, ações ou de pessoa física (DYER JR.; DYER, 2009).

Os principais desafios enfrentados constituem-se de demandas por níveis de profissionalização, estruturação administrativa de atividades, competitividade de mercado e perspectivas de continuidade dos negócios sobre direção da família (BORGES; LESCURA, 2012). No entanto, as abordagens teóricas e empíricas utilizadas são voltadas a problemas sobre conflitos entre a família e a continuidade da empresa, e só recentemente os pesquisadores tomaram iniciativas para avaliar o impacto da família na eficácia do negócio (DYER JR.; DYER, 2009).

Neste aspecto, Dyer Jr. e Dyer (2009) revelam que os fatores que impactam na performance das empresas familiares são os relacionados à capacidade e atuação de gestão e trabalho, capacidade e desempenho junto aos stakeholders, marca/imagem da família e a forma de aplicação do capital financeiro ou patrimônio físico. Os principais problemas encontrados estão ligados ao nepotismo e, como tal, envolvem critérios particulares para escolha de gestores e funcionários, além dos conflitos entre os familiares, principalmente na discussão do modelo de gestão a ser utilizado (DYER JR., 2010).

Observa-se uma diferença de maior performance quando comparado o líder fundador com a segunda geração. A partir destas informações, fica evidente a relação entre o perfil do líder e o desempenho do empreendimento rural. No entanto, nem sempre os resultados financeiros ou de retorno aos acionistas representam a eficácia de empresas familiares, existe uma preocupação diferente e está relacionada ao legado e à imagem da família perante a sociedade, a chamada riqueza socioemocional (DE TIENE; CHIRICO, 2013), a qual influencia as estratégias e decisões dos líderes e dos familiares.

Diante disso, a próxima seção versará sobre os indicadores de gestão utilizados na coleta de dados, sendo eles um composto do construto denominado Estilo de Gestão, cujas dimensões são Liderança, Decisão, Controle, Comunicação, Planejamento e Motivação, formando um instrumento validado semântica e empiricamente por Thiago (2017).

\subsection{Indicadores de gestão}

As dimensões que integram o Instrumento de Avaliação do Estilo de Gestão permitem entender o escopo desses termos, sendo elas: Liderança; Decisão; Comunicação; Controle; Objetivos, Metas ou Planejamento; e Motivação. Nessa perspectiva, Thiago (2017) elencou tais dimensões, as quais são apresentadas no Quadro 1.

Quadro 1 - Dimensões do construto Estilo de Gestão

\begin{tabular}{|l|l|}
\hline Dimensão & \multicolumn{1}{|c|}{ Autores que utilizaram } \\
\hline \multirow{3}{*}{ Liderança } & Likert (1967), Likert e Likert (1976), Morris e Pavett (1992), Culpan e \\
& $\begin{array}{l}\text { Kucukemiroglu (1993), Glunk, Wilderom e Ogilvie (1996), Blanco Jiménez, Fasci } \\
\text { e Valdez (2009), Gomes, Rangel e Resende et al . (2015), Gupta, Javadian e Jalili } \\
\text { (2014). }\end{array}$ \\
\hline
\end{tabular}




\begin{tabular}{|c|l|}
\hline Dimensão & \multicolumn{1}{|c|}{ Autores que utilizaram } \\
\hline Decisão & $\begin{array}{l}\text { Likert (1967), Likert e Likert (1976), Morris e Pavett (1992), Culpan e } \\
\text { Kucukemiroglu (1993), Blanco Jiménez, Fasci e Valdez (2009), Gomes, Rangel e } \\
\text { Resende (2015), Gupta, Javadian e Jalili (2014). }\end{array}$ \\
\hline Comunicação & $\begin{array}{l}\text { Likert (1967), Likert e Likert (1976), Morris e Pavett (1992), Culpan e } \\
\text { Kucukemiroglu (1993), Blanco Jiménez, Fasci e Valdez (2009), Gomes, Rangel e } \\
\text { Resende (2015). }\end{array}$ \\
\hline Controle & $\begin{array}{l}\text { Likert (1967), Likert e Likert (1976), Morris e Pavett (1992), Culpan e } \\
\text { Kucukemiroglu (1993), Glunk, Wilderom e Ogilvie (1996), Petry e Nascimento } \\
\text { (2009), Blanco Jiménez, Fasci e Valdez (2009), Gomes, Rangel e Resende (2015). }\end{array}$ \\
\hline Planejamento & $\begin{array}{l}\text { Likert (1967), Likert e Likert (1976), Morris e Pavett (1992), Petry e Nascimento } \\
\text { (2009), Blanco Jiménez, Fasci e Valdez (2009), Gomes, Rangel e Resende (2015), } \\
\text { Gupta, Javadian e Jalili (2014). }\end{array}$ \\
\hline Motivação & $\begin{array}{l}\text { Likert (1967), Likert e Likert (1976), Morris e Pavett (1992), Blanco Jiménez, } \\
\text { Fasci e Valdez (2009), Gomes, Rangel e Resende (2015). }\end{array}$ \\
\hline
\end{tabular}

Fonte: Adaptado de Thiago (2017, p. 37).

O Quadro 1 apresenta os indicadores de gestão utilizados por pesquisadores que investigaram organizações sob o aspecto sistêmico, buscando analisar a organização como um todo na percepção dos gestores, sendo estas dimensões as mais recorrentes entre estes autores.

Diante disso, serão abordados os aspectos teóricos evidenciados na teoria sobre cada um dos fatores utilizados na pesquisa, iniciando-se pelas teorias da liderança, passando pelas de decisão, comunicação, controle, planejamento e motivação:

Nas últimas décadas, a teoria da liderança transformacional tem ocupado a agenda das pesquisas deste tema, identificando três tipos de liderança: a transformacional, a transacional e a laissez-faire. O líder transformacional se preocupa em atender os desejos mais significantes de seus liderados, realizando o alinhamento dos interesses da gestão e dos colaboradores. Além disso, inspira-os a desenvolver soluções otimizadas, melhorando o ambiente de trabalho (CALAÇA; VIZEU, 2015).

O líder transacional mantém relação com seus liderados baseada em transações de trabalho/recompensa, a partir de um processo de troca para atender as atividades necessárias. O líder laissez-faire deixa as decisões e responsabilidades nas mãos dos colaboradores, evitando tomar decisões (CALAÇA; VIZEU, 2015).

O processo de decisão tem três correntes teóricas. A primeira é baseada na teoria de Simon (1945) e Graffin, Boivie e Carpenter (2013), em que a decisão é entendida como processo de julgamento racional - contudo, Simon (1945), especialmente, entende que as decisões são tomadas com base em uma racionalidade limitada, sendo fruto das interpretações momentâneas e do contexto. Outra corrente explica que o processo de decisão tem por base a política e o poder, partindo dos embates na arena política (CHILD; ELBANNA; RODRIGUES, 2010). Por fim, a terceira corrente, denominada Garbage Can, propõe que as decisões sejam tomadas fundamentadas por um fluxo caótico de informações e situações entre decisores, demandas e solutos (LOMI; CONALDI; TONELLATO, 2012).

Além disso, outro aspecto importante é a participação das pessoas no processo de decisão; quando ocorre, contribui no endossamento das pessoas, melhor efetivando os resultados organizacionais (ROBBINS; DECENZO, 2004). 
Em termos da gestão da comunicação, consideram-se processos que se realizam a partir do paradigma funcionalista, que, de acordo com Serra (2007), visa avaliar as informações transmitidas nas comunicações nas relações interpessoais ou para grupos. Este processo passa por mensagens codificadas, seguindo um fluxo do emissor a um receptor e seu respectivo feedback (SERRA, 2007).

As comunicações podem sofrer ruídos devido à falta de linearidade, flexibilidade e completude, dificultando a compreensão pelas pessoas que recebem as mensagens (IACOB; RISTEA, 2015).

Para Maguire e Hardy (2009), a comunicação é realizada com base no ambiente da organização e das relações sociais, dos quais os discursos influenciam e são influenciados pela cultura e identidade presentes no contexto que a organização está inserida.

O próximo indicador se refere aos instrumentos de controle organizacional. Para Simons (1995), trata-se de um sistema de indicadores isolados que se inter-relacionam, permitindo gerar informações e diagnóstico de toda a organização; geralmente, tem objetivo de verificar os níveis de desempenho e subsidiar decisões.

O controle é formado por sistemas positivos e negativos. O positivo é constituído por crenças e pelo sistema interativo que visam atribuir atenção aos gestores para melhor perceber as oportunidades e montar estratégias para executá-los. O negativo é estabelecido pelo sistema de diagnóstico e pelo sistema de advertências, propondo mecanismos para manter o alinhamento das ações aos objetivos estratégicos (SIMONS, 1995).

Mais um indicador, o de planejamento, permite identificar se a organização realiza as etapas definidas por Souza e Marinho (2014): estabelecimento da missão, valores e visão; diagnóstico para embasar a elaboração do planejamento; definição dos objetivos e metas; e definição da estratégia.

Por fim, o último indicador diz respeito às atividades que permitem motivar as pessoas na organização, para realizarem suas atividades com o melhor desempenho possível. Para tanto, são verificadas ações dos gestores, que utilizam fatores intrínsecos e extrínsecos. Os fatores intrínsecos são geradores de motivação, frutos de motivação interna das pessoas quando veem sentido no trabalho; são reconhecidos por desempenhar suas atividades, percebem-se realizados e despendem criatividade. Os extrínsecos são fatores de satisfação que, quando não presentes, geram desmotivação, correspondem às recompensas, estrutura de trabalho, natureza do trabalho e as relações entre colegas e supervisores (ERTAS, 2015).

Além disso, a literatura analisada indica que estes indicadores de gestão apreciados têm correlação direta com os resultados organizacionais. Neste aspecto, o planejamento de sucessão em organizações familiares, ou não, também são consideradas ações que fortalecem a sustentabilidade e longevidade organizacional, com a manutenção de sua competitividade. Assim, assume-se como hipótese de que as organizações que realizam o planejamento sucessório apresentam melhores resultados nos indicadores de gestão.

Com isso, a próxima seção apresenta os métodos utilizados para atendimento do objetivo desta pesquisa, de forma a testar a hipótese aqui apresentada.

\section{PROCEDIMENTOS METODOLÓGICOS}

Para o estudo em questão, foi utilizado método quantitativo, o qual trabalha com a lógica positivista e tende a enfatizar o raciocínio dedutivo e os atributos mensuráveis da experiência 
humana (GERHARDT; SILVEIRA, 2009). A escolha do método permitiu evidenciar a percepção do gestor no meio em que se insere quanto ao estilo de gestão.

Tendo em vista a utilização de um instrumento elaborado por Thiago (2017) para a coleta de dados sobre os indicadores de gestão das propriedades rurais de grande porte, o estudo partiu de um raciocínio dedutivo e, por tal característica, é quantitativo.

Quanto ao objetivo, o estudo foi descritivo, o qual é frequentemente utilizado para situações nas quais se pretende analisar atitudes, intenções e comportamentos. Descreve alguma coisa e caracteriza; para tanto, requer conhecimento prévio sobre o assunto, o que permite que a pesquisa seja planejada com antecedência e estruturada (GERHARDT; SILVEIRA, 2009).

A técnica de amostragem utilizada foi snowball, também chamada snowball sampling, ou "Bola de Neve", e consiste em interrogar um conjunto de atores, acrescentando informantes. Nela, os atores que farão parte da pesquisa são indicados diretamente pelos próprios pesquisados (BIERNACKI; WALDORF, 1981; ROTHENBERG, 1995).

A identificação dos participantes da pesquisa (e o recrutamento desses sujeitos) como atores sociais reconhecidos por seus pares ocorre por causa do papel de liderança no grupo estudado, conforme a metodologia snowball. Neste caso, a amostra foi constituída pelos gestores rurais e/ou produtores rurais que foram indicados e indicaram seus pares.

A partir dos dados fornecidos pelos sujeitos, os empreendimentos rurais foram caracterizados quanto a sua atividade e porte. Entre as diversas classificações quanto ao porte dos empreendimentos rurais, seguiu-se a classificação por módulos fiscais, na qual, nos termos da Lei Federal n. 8.629/1993 (BRASIL, 1993), considera-se propriedade pequena a que possui de 100 ha a 400 ha; média, acima de 400 ha a 1.500 há; e grande propriedade, acima de 1.500 ha, sendo a característica da amostra as que se classificam como grandes propriedades.

A técnica de amostragem Bola de Neve utiliza cadeias de referência e é não probabilística, por ser obtida com base em algum critério de inclusão; por isso, nem todos os elementos da população alvo têm a mesma oportunidade de seleção para participar da amostra (BIERNACKI; WALDORF, 1981; ROTHENBERG, 1995). A partir da técnica citada, o escopo do estudo compreendeu um grupo de dezesseis grandes produtores rurais mato-grossenses, aos quais, por meio de indicações entre os próprios gestores e/ou produtores rurais, foram enviados os questionários.

O contato com o grupo deu-se no período de julho a outubro de 2018, e os participantes estavam situados em diferentes macrorregiões de Mato Grosso, delimitação essa conforme o Instituto Mato-Grossense de Economia Agropecuária (IMEA, 2018). A abordagem para a pesquisa iniciou-se em um empreendimento localizado no Oeste de Mato Grosso, tendo sua principal atividade grãos e forrageiras com área de cultivo de 3.400 ha.

O instrumento para a coleta de dados constituiu-se de questionário dividido em dois blocos, sendo o primeiro criado pelos autores e destinado a caracterizar o objeto de estudo. No segundo bloco, constam itens relativos aos indicadores de gestão e foi utilizado o Instrumento de Avaliação do Estilo de Gestão validado por Thiago (2017), que considera os seguintes indicadores: Liderança, Decisão, Comunicação, Controle, Planejamento e Motivação, avaliados conforme sua classificação quanto à concordância do participante, medida por meio de uma escala tipo Likert.

Para teste da hipótese apresentada, foi utilizada técnica de estatística descritiva com comparação de média e do desvio-padrão das variáveis utilizadas em cada fator utilizado. A comparação de média das variáveis permite a análise do conjunto de dados de fator por fator. 
O modelo apresentado comparou os resultados das médias das respostas dos participantes da pesquisa separados nos grupos amostrais, sendo um formado por empreendimentos nos quais seus gestores e/ou proprietários disseram realizar planejamento de sucessão familiar e outro por aqueles que declararam não realizar.

\section{RESULTADOS E DISCUSSÃO}

Esta seção tem por objetivo estabelecer a relação entre planejamento de sucessão organizacional entre empresas familiares e os indicadores sobre o Estilo de Gestão, contudo, antes de iniciar os testes da hipótese elaborada, são apresentadas as características socioeconômicas das organizações participantes, listadas na Tabela 1.

Tabela 1 - Perfil do grupo de produtores pesquisados

\begin{tabular}{|c|c|c|c|}
\hline Característica & Perfil & Percentual & Quantidade \\
\hline Tipo de relação com a propriedade & $\begin{array}{l}\text { Proprietário } \\
\text { Gestor }\end{array}$ & $\begin{array}{l}37,5 \% \\
62,5 \%\end{array}$ & $\begin{array}{c}6 \\
10\end{array}$ \\
\hline Sexo & $\begin{array}{l}\text { Masculino } \\
\text { Feminino }\end{array}$ & $\begin{array}{l}69 \% \\
31 \%\end{array}$ & $\begin{array}{c}11 \\
5\end{array}$ \\
\hline Faixa etária & $\begin{array}{l}\text { De } 18 \text { a } 25 \text { anos } \\
\text { De } 26 \text { a } 35 \text { anos } \\
\text { De } 36 \text { a } 45 \text { anos } \\
\text { De } 46 \text { a } 55 \text { anos } \\
\text { Acima de } 55 \text { anos }\end{array}$ & $\begin{array}{c}19 \% \\
38 \% \\
31 \% \\
6 \% \\
6 \%\end{array}$ & $\begin{array}{l}3 \\
6 \\
5 \\
1 \\
1\end{array}$ \\
\hline Escolaridade & $\begin{array}{l}\text { Ensino médio completo } \\
\text { Superior incompleto } \\
\text { Superior completo } \\
\text { Pós-graduação incompleta } \\
\text { Pós-graduação completa }\end{array}$ & $\begin{array}{c}6 \% \\
19 \% \\
56 \% \\
6 \% \\
13 \%\end{array}$ & $\begin{array}{l}1 \\
3 \\
9 \\
1 \\
2\end{array}$ \\
\hline Funcionários fixos & $\begin{array}{l}20 \text { ou menos } \\
21 \text { a } 40 \\
41 \text { a } 50 \\
51 \text { a } 60 \\
61 \text { ou mais }\end{array}$ & $\begin{array}{c}50 \% \\
25 \% \\
19 \% \\
- \\
6 \%\end{array}$ & $\begin{array}{l}8 \\
4 \\
3 \\
- \\
1\end{array}$ \\
\hline Funcionários temporários & $\begin{array}{l}20 \text { ou menos } \\
21 \text { a } 40 \\
41 \text { a } 50 \\
51 \text { a } 60 \\
61 \text { ou mais }\end{array}$ & $\begin{array}{c}50 \% \\
25 \% \\
19 \% \\
- \\
6 \%\end{array}$ & $\begin{array}{l}8 \\
4 \\
3 \\
- \\
1\end{array}$ \\
\hline Principais produtos produzidos & $\begin{array}{l}\text { Grãos } \\
\text { Grãos, pecuária e outros } \\
\text { Grãos e forrageiras } \\
\text { Algodão } \\
\text { Pecuária } \\
\text { Outros: cana-de-açúcar }\end{array}$ & $\begin{array}{c}44 \% \\
31 \% \\
6 \% \\
6 \% \\
6 \% \\
6 \%\end{array}$ & $\begin{array}{l}7 \\
5 \\
1 \\
1 \\
1 \\
1\end{array}$ \\
\hline Gestor do empreendimento rural & $\begin{array}{l}\text { Esposo } \\
\text { Esposa } \\
\text { Filho(a) } \\
\text { Terceiro Contratado }\end{array}$ & $\begin{array}{c}6 \% \\
- \\
44 \% \\
50 \%\end{array}$ & $\begin{array}{l}1 \\
- \\
7 \\
8\end{array}$ \\
\hline Planejamento para sucessão familiar & $\begin{array}{l}\text { Sim } \\
\text { Não }\end{array}$ & $\begin{array}{l}75 \% \\
25 \%\end{array}$ & $\begin{array}{c}12 \\
4\end{array}$ \\
\hline
\end{tabular}

Fonte: Dados de pesquisa (2018). 
Cabe ressaltar, a partir da Tabela 1, que, das dezesseis propriedades rurais, todas têm área acima de 1.500 ha, definidas como grandes por terem área superior a 15 módulos, conforme a Lei n. 8.629/93 (BRASIL, 1993). Dos respondentes, 10 (62,5\%) são gestores e 6 (37,5\%) proprietários. São considerados jovens por estarem a maioria (38\%) na faixa etária entre 26 e 35 anos. Nota-se ainda a presença de mulheres em cinco locais (31,2\%).

Quanto à qualificação profissional, 56\% têm graduação, sendo cinco com graduação em Administração e quatro em Agronomia; e dois são pós-graduados na área de Gestão Administrativa. A maioria, oito empreendimentos (50\%), apresenta um quadro funcional fixo de até 20 funcionários, e somente um empreendimento tem 61 funcionários ou mais.

Como principais cultivos, sete locais (44\%) são produtores de grãos (soja, milho e feijão), e cinco $(31,2 \%)$, além de produzirem grãos, têm atividade pecuária. Os demais, um produz grãos e forrageiras, um produz algodão, um utiliza sua área para pecuária e um utiliza sua área total de 56.500 ha para produção de cana-de-açúcar. A maioria deles se localiza nas macrorregiões Centro-Sul e Oeste do Estado de Mato Grosso.

A próxima análise ressalta a comparação das médias dos indicadores de gestão em relação à sucessão organizacional. A Tabela 2 apresenta os dados da pesquisa, separando os resultados dos participantes que realizam sucessão dos que não realizam.

Tabela 2 - Relação entre planejamento de sucessão e indicadores de gestão

\begin{tabular}{|c|c|c|c|c|c|c|}
\hline \multirow{3}{*}{$\begin{array}{l}\text { Indicadores } \\
\text { de gestão }\end{array}$} & \multicolumn{4}{|c|}{ Planejamento de sucessão } & \multirow{2}{*}{\multicolumn{2}{|c|}{$\begin{array}{l}\text { Total dos indicadores } \\
\text { de gestão }(n=16)\end{array}$}} \\
\hline & \multicolumn{2}{|c|}{$\operatorname{Sim}(n=12)$} & \multicolumn{2}{|c|}{ Não $(n=4)$} & & \\
\hline & Média & Desvio-padrão & Média & Desvio-padrão & Média & Desvio-padrão \\
\hline Liderança & 4,19 & 0,74 & 3,58 & 0,57 & 4,04 & 0,74 \\
\hline Decisão & 3,75 & 1,16 & 3,33 & 0,47 & 3,65 & 1,03 \\
\hline Comunicação & 3,77 & 1,06 & 3,19 & 0,43 & 3,63 & 0,96 \\
\hline Controle & 3,93 & 1,08 & 3,35 & 0,64 & 3,79 & 1,01 \\
\hline Planejamento & 3,82 & 1,10 & 3,20 & 0,49 & 3,66 & 1,00 \\
\hline Motivação & 4,28 & 0,90 & 3,80 & 0,59 & 4,16 & 0,84 \\
\hline $\begin{array}{l}\text { Média dos } \\
\text { indicadores }\end{array}$ & 3,96 & 0,99 & 3,41 & 0,51 & 3,82 & 0,91 \\
\hline
\end{tabular}

Fonte: Dados da pesquisa (2018).

De acordo com os dados apresentados na Tabela 2, observa-se que as organizações de grande porte que realizam o planejamento de sucessão têm indicadores de gestão mais bem avaliados (média $=3,96$ ) quando se compara com as que não o realizam (média =3,41).

Este resultado evidencia a necessidade de práticas de gestão apreciadas pela academia que, nos casos, denotam melhores resultados, em especial no quesito planejamento de sucessão familiar, conforme verificado por Borges e Lescura (2012) e Dyer Jr. e Dyer (2009).

Ainda sobre este aspecto, verificou-se que os empreendimentos rurais que não realizam planejamento sucessório apresentam menor avaliação dos indicadores de gestão, com média de 3,41. De Tiene e Chirico (2013) discutem esta questão, podendo neste caso ter a preocupação de manutenção do legado e do estilo de gestão familiar, o que pode comprometer, em alguns casos, seu desempenho.

Outros resultados complementares apresentados são as diferenças de percepções ao se analisar os desvios médios (SD). Nestes, quanto mais as respostas do grupo se aproximam da média, 
maior a consistência. A maior consistência está na dimensão Liderança, para os que planejam sucessão $(S D=0,74)$, e em Comunicação, para os que não planejam ( $S D=0,43)$. Os conjuntos de percepções com menor consistência quando comparados os desvios médios são Decisão, para os que planejam sucessão, (SD = 1,16) e Controle, para os que não planejam (SD =0,64).

Observa-se ainda que os empreendimentos agropecuários de grande porte analisados apresentam melhores indicadores de gestão nas dimensões Liderança (média $=4,04$ ) e Motivação (média $=4,16$ ), o que denota a importância do papel do líder e das práticas inter-relacionais. Contudo, a dimensão Comunicação (média $=3,63$ ) obteve a menor avaliação em relação às outras, semelhante ao resultado obtido por Thiago (2017).

Os empreendimentos analisados têm como característica a presença de gestor profissional em $50 \%$, ou seja, a gestão não está sob responsabilidade de um membro da família. Considerando ser este um dado relevante para a análise sobre planejamento da sucessão, a Tabela 3 apresenta os dados dos indicadores de gestão entre os gestores que são membros da família e os que são gestores contratados (não membros da família).

Tabela 3 - Relação entre tipo de gestor e indicadores de gestão

\begin{tabular}{|c|c|c|c|c|}
\hline \multirow{3}{*}{$\begin{array}{l}\text { Indicadores } \\
\text { de gestão }\end{array}$} & \multicolumn{4}{|c|}{ Gestor } \\
\hline & \multicolumn{2}{|c|}{ Da família ( $n=8)$} & \multicolumn{2}{|c|}{ Contratado $(n=8)$} \\
\hline & Média & Desvio-padrão & Média & Desvio-padrão \\
\hline Liderança & 4,25 & 0,73 & 3,83 & 0,73 \\
\hline Decisão & 3,79 & 1,07 & 3,50 & 1,04 \\
\hline Comunicação & 3,72 & 1,05 & 3,53 & 0,93 \\
\hline Controle & 3,85 & 1,16 & 3,73 & 0,90 \\
\hline Planejamento & 3,68 & 1,03 & 3,65 & 1,05 \\
\hline Motivação & 4,23 & 0,89 & 4,10 & 0,84 \\
\hline Média dos indicadores & 3,92 & 0,98 & 3,72 & 0,90 \\
\hline
\end{tabular}

Fonte: Dados da pesquisa (2018).

Os dados apresentados pela Tabela 3 evidenciam melhor percepção dos gestores sobre sua performance no grupo dos gestores da família (média $=3,92$ ) quando se compara com o grupo dos gestores contratados que não pertencem à família (média $=3,72$ ).

O proprietário ou membro da família possivelmente mantém o estilo de gestão passado de geração em geração que proporcionou o desenvolvimento até então, estabelecendo os valores, rituais, regras e demais dinâmicas que compõem a cultura da organização aos moldes do citado por Freitas (2007); uma ruptura neste padrão, por meio de um processo de sucessão, passando a gestão para um não membro da família, pode gerar deficiências caso não haja um planejamento prévio.

Entre os indicadores observados, o Quadro 2 ranqueia os melhores resultados nos dois grupos de gestores. 
Quadro 2 - Ranking dos resultados nos grupos de gestores membros da família e não membros da família/contratados

\begin{tabular}{|c|c|c|}
\hline Ranking & Gestor membro da família & Gestor contratado \\
\hline 1 o & Liderança & Motivação \\
\hline 20 & Motivação & Liderança \\
\hline 3 o & Controle & Controle \\
\hline $4 ㅇ$ & Decisão & Planejamento \\
\hline 50 & Comunicação & Comunicação \\
\hline 60 & Planejamento & Decisão \\
\hline
\end{tabular}

Fonte: Dados da pesquisa (2018).

Conforme apresentado no Quadro 2, as comparações dos indicadores mostram melhor percepção dos gestores membros da família nas dimensões Liderança e Motivação, com média de 4,25 e 4,23, respectivamente, sendo mais preteridas as dimensões Comunicação (média = 3,72 ) e Planejamento (média $=3,68$ ). Para o outro grupo, destacam-se a dimensão Motivação, com média de 4,10, e a dimensão Decisão, com a menor percepção de eficiência entre os indicadores, com média de 3,5.

A maior diferença entre os indicadores é percebida ao se comparar os gestores no quesito Liderança, o qual teve média de 4,25 para os gestores membros da família e de 3,83 aos gestores não membros/contratados.

Um aspecto a ser observado é em termos das ações de planejamento e decisão. No grupo dos gestores familiares, a variável Decisão é mais bem avaliada quando comparada à de Planejamento. Já o contrário ocorre no grupo dos gestores não familiares, junto aos quais o item Planejamento é mais bem avaliado em relação à Decisão.

Em suma, observa-se que, nos grupos de empreendimentos rurais que dizem pensar a sucessão, há melhores resultados quando se compara com os que não realizam sucessão. Esta evidência é reforçada quando se observam os resultados dos gestores familiares e não familiares, mostrando que os gestores familiares têm melhores resultados nos indicadores de gestão analisados (média $=3,92$ contra média $=3,72$ ), possivelmente por realizarem sucessão, mesmo que de forma não planejada.

Diante dos resultados apresentados, nota-se a necessidade de maior atenção aos aspectos pertinentes à gestão nos empreendimentos rurais analisados, visto que, em termos de tecnologia, empiricamente observado e na literatura, há apontamentos que estão satisfatoriamente atendidos, especialmente nos grandes empreendimentos (SZNITOWSKI, 2017; THIAGO, 2017; HUBBARD; ALVIM; GARROD, 2017; MOREDDU; CONTINI; ÁVILA, 2017).

\section{CONSIDERAÇÕES FINAIS}

Os estudos em organizações do agronegócio têm sido recorrentes nos periódicos brasileiros, porém os aspectos relacionados à gestão como um todo têm sido incipientes. Diante disso, gestores e pesquisadores têm considerado a gestão como uma nova fronteira para a obtenção de melhores resultados nas organizações agropecuárias, embora muitas delas fossem referências de produtividade, resultado principalmente dos esforços tecnológicos. Soma-se a isso a ausência de discussões sobre um tema relevante e ao mesmo tempo complexo: o processo sucessório em empreendimentos rurais, o qual é favorecido por uma gestão estruturada. 
Com objetivo de contribuir para esta discussão, tem-se por atendido o objetivo da pesquisa de analisar/relacionar os resultados dos indicadores de gestão com o planejamento de sucessão, evidenciando que há diferença nos indicadores de gestão entre os dois grupos analisados quanto à realização do planejamento de sucessão, como nos gestores membros da família e contratados não membros da família. Neste ponto, observou-se que os empreendimentos que planejam sucessão têm a sua frente membros da família e apresentam melhor desempenho nos indicadores investigados quando comparados aos com gestores não membros da família.

As melhores percepções de desempenho dos indicadores de gestão estão presentes quando esta prática aparece nos empreendimentos rurais analisados corroborada pelos resultados de comparações entre o desempenho de gestores componentes da família e gestores não familiares. Esta última análise permite a elaboração da hipótese de que estas organizações mantêm o planejamento sucessório no seio familiar, repassando e aperfeiçoando as técnicas de gestão e a cultura organizacional entre as gerações.

A contribuição do estudo se dá por apresentar um estilo de gestão utilizado pelos empreendimentos agropecuários de grande porte pertencentes ao Estado de Mato Grosso, líder em produção de commodities no Brasil e mundialmente representativo, e este estilo pode ser discutido em outras organizações de outras localizações, inclusive na forma de benchmarking.

Quanto às limitações do estudo, são as pertinentes ao tamanho e tipo da amostra, considerando a dificuldade em acessar os gestores, somadas à demora no retorno de algumas respostas, decorrente do fato de o produtor/gestor rural não dispor de tempo para responder ao questionário, uma vez que estava no início de plantio da lavoura 2018/2019, que se deu, em partes, quando estava sendo aplicada a pesquisa, de julho a outubro de 2018.

\section{REFERÊNCIAS}

BIERNACKI, P.; WALDORF, D. Snowball sampling: problems and techniques of Chain Referral Sampling. Sociological Methods \& Research, v. 10, n. 2, p. 141-63, nov. 1981.

BLANCO JIMÉNEZ, M.; FASCI, M. A.; VALDEZ, J. A Comparison of management style for Mexican firms in Mexico and the Unit States. International Journal of Business, v. 14, n. 3, p. 251-63, 2009.

BORGES, A. F.; LESCURA, C. Sucessão em empresas familiares: um olhar sobre a pesquisa brasileira. In: ENCONTRO DA ASSOCIAÇÃO NACIONAL DE PÓS-GRADUAÇÃO E PESQUISA EM ADMINISTRAÇÃO, 36., 2012, Rio de Janeiro. Anais [...]. Rio de Janeiro: ANPAD, 2012.

BRASIL. Lei n. 8629, de 25 de fevereiro de 1993. Dispõe sobre a regulamentação dos dispositivos constitucionais relativos à reforma agrária, previstos no Capítulo III, Título VII, da Constituição Federal. Brasília-DF, 1993.

CALAÇA, P. A.; VIZEU, F. Revisitando a perspectiva de James MacGregor Burns: qual é a ideia por trás do conceito de liderança transformacional? Cadernos EBAPE.BR, Rio de Janeiro, v. 13, n. 1, p. 121-35, 2015.

CHILD, J.; ELBANNA, S.; RODRIGUES, S. The political aspects of strategic decision making. In: NUTT, P. C.; WILSON, D. C. (Edit.). Handbook of Decision Making. West Sussex: Wiley, 2010. p. 105-37.

CONFEDERAÇÃO DA AGRICULTURA E PECUÁRIA DO BRASIL. Mato Grosso exporta US\$ 5,2 bilhões em produtos agropecuários nos primeiros quatro meses do ano. Brasília: CNA, 2018. Disponível em: http:// www.cnabrasil.org.br/noticias/mato-grosso-exporta-us-52-bilhoes-em-produtos-agropecuarios-nosprimeiros-quatro-meses-do. Acesso em: 24 maio 2018. 
CULPAN, R.; KUCUKEMIROGLU, O. A Comparison of U.S. and Japanese Management Styles and Unit Effectiveness. Management International Review, v. 33, n. 1, p. 27-42, 1993.

DAVIS, J. H.; GOLDBERG, R. A. The concept of agribusiness. Boston: Harvard University, 1957.

DE TIENE, D. R.; CHIRICO, F. Exit strategies in family firms: how socioemotional wealth drives the threshold of performance. Entrepreneurship Theory and Pratice, v. 37, n. 6, p. 1297-318, 2013.

DYER JR., W. G. Are you the right type of family business. Organizational Dynamics, v. 39, n. 3, p. 269-78, 2010. DOI: https://doi.org/10.1111/ijmr.12167

DYER JR., W. G.; DYER, W. J. Putting the Family into Family Business Research. Family Business Review, v. 22, n. 3, p. 216-19, 2009. DOI: https://doi.org/10.1177\%2F0894486509333042

ERTAS, N. Turnover intentions and work motivations of millennial employees in federal service. Public Personnel Management, v. 44, n. 3, p. 401-23, 2015.

FREITAS, M. E. Cultura organizacional - evolução e crítica. São Paulo: Cengage Learning, 2007.

GERHARDT, T. E.; SILVEIRA, D. T. Métodos de Pesquisa. Porto Alegre: UFRGS, 2009.

GLUNK, U.; WILDEROM, C.; OGILVIE, R. Finding the key to German-style management. International Studies of Management \& Organization, v. 26, n. 3, p. 93-108, 1996.

GOMES, L. F. A. M.; RANGEL, L. A. D.; RESENDE, R. C. Prioritization of telecommunication projects: decision analysis using the prométhée v method. Revista Economia \& Gestão, Belo Horizonte, v. 15, n. 41, p. 311 $32,2015$.

GRAFFIN, S. D.; BOIVIE, S.; CARPENTER, M. A. Examining CEO succession and the role of heuristics in early-stage CEO evaluation. Strategic Management Journal, v. 34, n. 4, p. 383- 403, 2013.

GUPTA, V. K.; JAVADIAN, G.; JALILI, N. Role of entrepreneur gender and management style in influencing perceptions and behaviors of new recruits: evidence from the Islamic Rebublic of Iran. Journal of International Entrepreneurship, v. 12, p. 85-109, mar. 2014.

HUBBARD, H. ALVIM, A. M.; GARROD, G. Brazilian agriculture as a global player. EuroChoices, v. 16, n. 1, p. 3-4, 2017.

IACOB, C. C.; RISTEA, A. L. Organizational Communication and Management of Risk Situations. Valahian Journal of Economic Studies, v. 6, n. 1, p 27-32, 2015.

INSTITUTO MATO-GROSSENSE DE ECONOMIA E AGROPECUÁRIA. Conjuntura econômica. Cuiabá: IMEA, 2018. Disponível em: http://www.imea.com.br/upload/publicacoes/arquivos/07052018204242.pdf. Acesso em: 23 maio 2018.

LEONARD, B.; KINSELLA, A; O'DONOGHUE, C; FARRELL, M; MAHON, M. Policy drivers of farm succession and inheritance. Land Use Policy, v. 61, p. 147-59, 2017. DOI: https://doi.org/10.1016/j.landusepol.2016.09.006

LIKERT, R. The human organization: its management and value. Nova lorque: MacGraw-Hill, 1967.

LIKERT, R.; LIKERT, J. G. New ways of managing conflict. Nova lorque: MacGraw-Hill, 1976.

LOMI, A.; CONALDI, G.; TONELLATO, M. Organized Anarchies and the Network Dynamics of Decision Opportunities in an Open Source Software Project. In: LOMI, A.; HARRISON, R. (Eds.). The garbage can 
model of organizational choice: looking forward at forty. Emerald Press, 2012. p. 363-97. (Research in the Sociology of Organizations, v. 36).

MAGUIRE, S.; HARDY, C. Discourse and Deinstitutionalization: the Decline of DDT, Academy Management Journal, v. 52, n. 1, p. 148-78, 2009.

MATTE, A.; MACHADO, J. A. D. Tomada de decisão e a sucessão na agricultura familiar no sul do Brasil. Revista de Estudos Sociais, Cuiabá, v. 18, n. 37, p. 130-51, 2016. Disponível em: http://periodicoscientificos. ufmt.br/ojs/index.php/res/article/view/3981. Acesso em: 23 maio 2018.

MINISTÉRIO DA AGRICULTURA, PECUÁRIA E ABASTECIMENTO. Agropecuária Brasileira em Números. Brasília-DF: MAPA, 2019. Disponível em: http://www.agricultura.gov.br. Acesso em: 2 jul. 2019.

MOREDDU, C.; CONTINI, E.; ÁVILA, F. Challenges for the Brazilian Agricultural Innovation System. EuroChoices, v. 16, n. 1, p. 26-31, 2017.

MORRIS, T.; PAVETT, C. M. Management style and productivity in two cultures. Journal of International Business Studies, v. 23, n. 1, p. 169-79, 1992.

OLIVEIRA, W. M.; VIEIRA FILHO, J. E. R. Sucessão nas fazendas familiares: problemas e desafios. Texto para discussão - Instituto de Pesquisa Econômica Aplicada. Brasília-DF: IPEA, 2018.

PETRY, L. I.; NASCIMENTO, A. M. Um estudo sobre o modelo de gestão e o processo sucessório em empresas familiares. Revista Contabilidade \& Finanças, v. 20, n. 49, p. 109-25, jan./abr. 2009.

PINTO, L. C. G. Política Agrícola. In: RODRIGUES, R. Agro é paz: análises e propostas para o Brasil alimentar o mundo. Piracicaba: ESALQ, 2018. p. 71-110.

REZENDE, C. L.; ZYLBERSZTAJN, D. Uma análise da complexidade do gerenciamento rural. In: SEMINÁRIOS DE ADMINISTRAÇÃO, 4., 1999, São Paulo. Anais [...]. São Paulo: USP, 1999.

ROBBINS, S. P.; DECENZO, D. A. Fundamentos de administração: conceitos essenciais e aplicações. 4. ed. São Paulo: Prentice Hall, 2004.

ROTHENBERG, R. B. Commentary: sampling in social networks. Connections, Florida, v. 18, n. 1, p. 10410, 1995.

SEBRAE. Como planejar a sucessão familiar. 2018. Disponível em: http://www.sebrae.com.br/sites/ PortalSebrae/ufs/ap/artigos/. Acesso em: 30 abr. 2018.

SERRA, J. P. Manual de teoria da comunicação. Covilhã: Universidade Beira Interior, 2007.

SIMON, H. A. Administrative behavior: a study of decision-making processes in administrative organization. Nova lorque: Macmillan Co., 1945.

SIMONS, R. Levers of control: how managers use innovative control systems to drive strategic renewal. Boston: Harvard Business School, 1995.

SOUZA, S. C.; MARINHO, S. V., Planejamento estratégico baseado no Balanced Scorecard: um estudo de caso aplicado a uma pequena empresa de segurança. Revista Gestão \& Planejamento, Salvador, v. 15, n. 2, p. 213-37, maio/ago. 2014.

SZNITOWSKI, A. M. Uma análise sobre a capacidade absortiva em unidades de produção de soja no Estado de Mato Grosso (Brasil). 2017. 194 f. Tese (Doutorado em Administração) - Universidade do Vale do Rio dos Sinos (UNISINOS), São Leopoldo, RS, 2017. 
THIAGO, F. Estilo de Gestão dos Produtores Rurais Brasileiros. 2017. 197 f. Tese (Doutorado em Administração, área de concentração: Gestão e Regionalidade) - Universidade Municipal de São Caetano do Sul [USCS], São Caetano do Sul, SP, 2017.

THIAGO, F.; KUBO, E. K. M.; PAMPLONA, J. B.; FARINA, M. C. Estilo de Gestão de Produtores Rurais. Revista de economia e sociologia rural, Brasília, v. 58, n. 2, p. 1-18, 2020. Disponível em: http://dx.doi. org/10.1590/1806-9479.2020.188254. Acesso em: 2 de maio de 2021.

VILCKAS, M., NANTES, J. F. D.; ZUIN, L. F., QUEIROZ, T. R. (Org.). Planejamento e agregação de valor nos empreendimentos rurais. São Paulo: Saraiva, 2006.

\section{Sobre os autores:}

Adelice Minetto Sznitowski: Doutora em Administração pela Universidade do Vale do Rio dos Sinos (UNISINOS). Mestre em Engenharia de Produção pela Universidade Federal de São Carlos (UFSCar). Graduada em Administração pela Universidade do Estado de Mato Grosso (UNEMAT). Especialista em Didática do Ensino Superior. Atualmente, é professora adjunta naUniversidade do estado de Mato Grosso (UNEMAT). Coordena e participa de projetos de pesquisa com foco em tecnologia, gestão e absorção de conhecimento, voltados ao Agronegócio. Atua em projeto de extensão e pesquisa aplicada na área de gestão em empreendimentos rurais. Integra o Banco de Avaliadores do Sistema Nacional de Avaliação da Educação Superior (BASIs). E-mail: adelice.minetto@unemat.br, Orcid: http://orcid.org/0000-0003-3184-2342

Priscylla Cordeiro de Sousa: Graduada em Administração pela Universidade do Estado de Mato Grosso (UNEMAT). Assistente de negócios do Banco SICREDI. E-mail: priscylla.cordeiro@unemat.br, Orcid: https://orcid.org/0000-0003-4521-4523

Fernando Thiago: Doutor em Administração pela Universidade Municipal de São Caetano do Sul (USCS). Mestre em Ciências Ambientais e especialista em Gestão Pública pela Universidade do Estado de Mato Grosso (UNEMAT). Magistério do Ensino Superior pelo Instituto Brasileiro de PósGraduação e Extensão (IBPEX). Graduado em Administração pela Centro Universitário de Mineiros. Atualmente é professor da Educação Superior do Campus do Pantanal da Universidade Federal de Mato Grosso do Sul (UFMS). Atua nos seguintes temas: Gestão Pública, Gestão de Pessoas e Gestão do Agronegócio. E-mail: fernando.t@ufms.br, Orcid: http://orcid.org/0000-0002-7947-0667 